\title{
A Survey of Cost Estimating Methodologies for Distributed Spacecraft Missions
}

\author{
Veronica L. Foreman ${ }^{*}$ Jacqueline Le Moigne ${ }^{\dagger}$, and Olivier L. de Weck ${ }^{\star}$ \\ Massachusetts Institute of Technology Department of Aeronautics \& Astronautics, Cambridge, MA, 02139 \\ NASA Goddard Space Flight Center, Greenbelt, MD, 20771
}

\begin{abstract}
Satellite constellations present unique capabilities and opportunities to Earth orbiting and near-Earth scientific and communications missions, but also present new challenges to cost estimators. An effective and adaptive cost model is essential to successful mission design and implementation, and as Distributed Spacecraft Missions (DSM) become more common, cost estimating tools must become more representative of these types of designs. Existing cost models often focus on a single spacecraft and require extensive design knowledge to produce high fidelity estimates. Previous research has examined the shortcomings of existing cost practices as they pertain to the early stages of mission formulation, for both individual satellites and small satellite constellations. Recommendations have been made for how to improve the cost models for individual satellites one-at-a-time, but much of the complexity in constellation and DSM cost modeling arises from constellation systems level considerations that have not yet been examined. This paper constitutes a survey of the current state-of-theart in cost estimating techniques with recommendations for improvements to increase the fidelity of future constellation cost estimates. To enable our investigation, we have developed a cost estimating tool for constellation missions. The development of this tool has revealed three high-priority weaknesses within existing parametric cost estimating capabilities as they pertain to DSM architectures: design iteration, integration and test, and mission operations. Within this paper we offer illustrative examples of these discrepancies and make preliminary recommendations for addressing them. DSM and satellite constellation missions are shifting the paradigm of space-based remote sensing, showing promise in the realms of Earth science, planetary observation, and various heliophysical applications. To fully reap the benefits of DSM technology, accurate and relevant cost estimating capabilities must exist; this paper offers insights critical to the future development and implementation of DSM cost estimating tools.
\end{abstract}

$\begin{array}{ll}C E R & =\text { Cost Estimating Relationship } \\ D S M & =\text { Distributed Spacecraft Mission } \\ E S T O & =\text { Earth Science Technology Office } \\ M M S & =\text { Magnetospheric Multiscale Mission } \\ N A S A & =\text { National Aeronautics and Space Administration } \\ R D T E & =\text { Research, design, test, and evaluation } \\ S T 5 & =\text { Space Technology } 5 \text { Mission } \\ T A T-C & =\text { Tradespace Analysis Tool for Constellations } \\ T R L & =\text { Technological Readiness Level } \\ W B S & =\text { Work Breakdown Structure }\end{array}$

\footnotetext{
* Dual Master's Candidate and National Science Graduate Research Fellow, MIT Department of Aeronautics and Astronautics, Technology and Policy Program. Building 33-409. AIAA Student Member.

${ }^{\dagger}$ Assistant Chief for Technology, Software Engineering Division. NASA GSFC, Greenbelt, MD, 20771, Code 580.

* Professor, Massachusetts Institute of Technology Department of Aeronautics and Astronautics. MIT Building 33410, Cambridge, MA 02139. AIAA Associate Fellow.
} 


\section{Introduction}

$\mathrm{S}_{\mathrm{n}}^{\mathrm{A}}$ ATELLITE constellations present unique capabilities and opportunities to earth observing and communications missions, but also present new challenges to cost estimators. These new capabilities include increased science data volume, increased revisit frequency, multi-angle sensing capabilities, scalability, and decreased mission cost, among others [1]. Satellite constellations and distributed spacecraft mission (DSM) architectures enable the mission architect to deploy several satellites in support of a common goal (or goals) and thereby offer opportunities for multiplatform data gathering and analysis that have not been available using previous technology. For example, the value of NASA's Landsat Program is grounded in the wide range of data available to analysts and policy makers, enabled by the use of multiple satellites deployed over the span of nearly half a century. Each element of the Landsat Program has contributed incrementally to the collection of Earth satellite imagery and has consequently added to the value of the existing dataset. The Gravity Recovery and Climate Experiment (GRACE) utilized two identical spacecraft to measure variations in the Earth's gravity field and highlighted the value of multiple satellites working in support of a common mission objective [2].

Despite past success and recent enthusiasm, the field of Earth Science has been slow to adopt DSM architectures and has instead continued to utilize traditional, monolithic satellite designs, unless the mission objective specifically requires the use of multiple observatories. The initial hesitancy to adopt DSMs for Earth science applications may be rooted in the perception that constellation missions are either technologically or economically prohibitive. These concerns regarding DSMs are not limited to the Earth science community. A 2014 report by the Government Accountability Office (GAO) addressed the need for additional knowledge before decisions regarding the US Air Force proposal to pursue satellite disaggregation, the process of decomposing large, highly complex satellites (or constellations) into smaller, less individually complex 'systems of systems' could be finalized. The GAO cited uncertainty regarding both the magnitude of the benefits and the severity of risks as potential barriers to widespread use of disaggregated space systems, as well as the short term costs that might be associated with the cultural transition to disaggregated mission implementation [3]. However, recent developments in small satellite technology and intersatellite communication links have made DSM architectures more feasible than ever before, and Earth science programs are uniquely poised to take advantage of these technologies. Cubesatellite and small satellite (mass $<100 \mathrm{~kg}$ ) constellation missions, which fall within NASA's Class D mission category, can accept more risk than missions with higher classifications, and are more likely to demonstrate or contribute to technologies that will be flown in the future. Small satellite DSMs can not only pave the way for larger programs, but they can also provide valuable data to the Earth science community in the process.

DSM architectures are emerging as essential tools for the future of Earth observation. The NASA Earth Science Technology Office (ESTO) specifically included satellite constellation and formation flying missions in its 2030 Science Vision as technologies that can enable the next generation of Earth science [4]. The first competitivelyselected, space-based Earth Venture Mission proposal chosen for development by NASA under the Earth System Science Pathfinder (ESSP) program was awarded in 2012 to a constellation of eight microsatellites, the Cyclone Global Navigation Satellite System (CYGNSS), and was praised as both a "scientific and programmatic advance for NASA's Earth science and applications program" [5].

Previous research has examined the shortcomings of existing cost practices as they pertain to the early stages of mission formulation, for both individual satellites and small satellite constellations [6,7]. Among these shortcomings is a tendency to underestimate the cost growth of Earth and Space Science missions [8]. An effective and adaptive cost model is essential to successful mission design and implementation, and as DSMs become more common, cost estimating tools must become more representative of these types of designs. This has the potential to not only enable individual mission success, but also to promote more widespread use of DSM architectures for Earth observation.

Commercial satellite communications companies have already begun incorporating DSM architectures into their business models to leverage economies of scale and learning curve benefits, and recent trends seem to suggest that the strategy has been successful. Iridium Satellite Communications, founded in 2001, is scheduled to begin launching its Iridium Next constellation this year, but has already begun working on development plans for subsequent spacecraft. The company has argued that Thales Alenia Space, which was responsible for building 81 Iridium Next satellites, has a competitive advantage in that it has already mass-produced Iridium satellites and could transform that advantage into substantial cost savings if manufacturing efforts on the next satellites can begin relatively soon [9]. Similarly, OneWeb Satellites has begun development of a satellite constellation manufacturing facility in Florida that is expected to be the birth place of nearly 900 satellites between now and the constellation's anticipated 2018 launch $[9,10]$.

Earth science research missions, in contrast to highly uniform and commercial communications systems, often employ new technologies, low flight heritage instrumentation, or large sensor suites, the complexity of which is 
magnified when incorporated within a distributed system. Consequently, DSM efforts in the realm of Earth observation thus far have included relatively few spacecraft. The GRACE mission, as mentioned previously, consisted of only two spacecraft that were launched together in 2002 [2], and the Magnetospheric Multiscale Mission (MMS), a set of four identical spacecraft designed to examine magnetic reconnection, launched in 2015 [11]. Recent awards and project proposals including CYGNSS and the Time-Resolved Observations of Precipitation structure and storm Intensity with a Constellation of Smallsats (TROPICS) mission, which consists of 12 identical $3 \mathrm{U}$ cube satellites [12], show that while DSMs with a greater number of spacecraft are being developed, they are often relying on smaller satellites, which also have particular costing challenges [13,14].

Maximizing the benefits of DSM architectures and understanding their cost proflies will require a deeper understanding of the nuances associated with the DSM lifecycle. Early mission phases, including Phase A and Phase B design, may require adaptations of existing engineering processes or development of entirely new approaches to design, manufacturing, integration and test. Initial efforts to optimize constellation architectures with respect to performance, measured in terms of maximum revisit time or similar coverage metrics, have sought to address often competing DSM design objectives, such as minimizing cost while maximizing science data volume. These works have tended to result in a set of possible solutions rather than a single optimum design, and the tradeoff analysis methods necessary to select a design from the solution set has been a fruitful ground for research $[15,16]$. Others have addressed later phases of mission development: Wertz and Larson have argued that traditional satellite manufacturing, integration, and test practices will needlessly increase the cost and schedule demands of constellation programs, and have called for greater incorporation of concurrent engineering practices and emphasis on high quality processes as a method of ensuring high quality products [17]. Once constructed and fit for flight, the spacecraft must be launched in a manner that minimizes system cost without compromising safety. A 2008 seminar series conducted by Honeywell Technology Solutions, Inc. and NASA Goddard Space Flight Center (GSFC) focused on the best practices of constellation operations, noting that significant events in past constellation programs have tended to shape the DSM development culture [18]. For example, the deployment strategy may include several different configurations, placing spacecraft as either primary or secondary payloads, and launch providers, leveraging different launch services to achieve specific orbit configurations or to minimize the threat of launch failure to the lifetime of the DSM. Operation of the spacecraft once in orbit follows a similar approach seeking to minimize cost without increasing the risk. This has manifested itself as the increased use of intersatellite links, automated ground station tasks, and changes to ground system resources, including personnel and anomaly identification and tracking systems.

Each of these challenges and mitigation strategies has an impact on overall mission cost, and there has been limited effort to identify the appropriate cost estimating approach for DSMs given these developments. Optimization efforts that have considered mission cost have typically employed cost estimating relationships (CERs) that were developed for monolithic spacecraft $[15,16]$. This approach presents two obstacles to high fidelity constellation cost estimating. First, all CERs are developed based on historical data sets, and therefore, an underlying assumption is that historical trends will hold for the foreseeable future. The application of existing CERs to DSM architectures, which often leverage advanced or specialized technology, may be inappropriate. Second, there has been a tendency in early optimization efforts to estimate the total mission cost for a DSM containing $n$ identical spacecraft by calculating the cost of one spacecraft and then multiplying it $n$ times. This method fails to account for benefits of developing multiple spacecraft simultaneously, such as economies of scale and learning curve advantages, and similarly fails to address the additional cost-risk associated with late design changes or manufacturing errors [19]. The underlying assumptions regarding the design and manufacturing process may therefore be challenged by the emerging DSM paradigm.

Given the importance of accurate cost estimating to the success of mission proposals, and the ever increasing scrutiny of how scientific agencies spend tax payer dollars, an accurate cost estimating approach for constellations is an essential development tool for DSMs. This paper discusses an attempt to apply the existing costing toolset to DSM architectures in the form of a preliminary, aggregated costing tool. This attempt, building upon the work presented by Nag et. al in their 2014 work [7], revealed three gaps within the existing cost estimating toolset; we argue that improvements to these areas could increase the accuracy of future constellation cost estimates. This paper addresses the outcome of the survey we conducted and gaps in the constellation cost estimating toolkit that we encountered while building our aggregated model. The model itself will be leveraged as part of a larger effort, being led by NASA Goddard Space Flight Center (GSFC) to develop Tradespace Analysis Tool for Constellations (TATC). We will present the specific details and results of the aggregated cost model in a later paper, once TAT-C has been released.

In the second section of this paper, we present necessary background for the fields of both DSM architectures and parametric cost estimating, and discuss previous work related to these research areas. In the third section, we 
outline our methodology and the development of the aggregate cost model. In the fourth section, we present our observations and recommendations regarding the future of DSM cost estimating efforts, based on our survey of the current cost tools available to DSM project managers and our work developing the aggregate cost model. In the fifth section, we present our conclusions and plans for future work.

\section{Background}

This paper lies at the intersection of DSM optimization and cost estimation research, and as such some preliminary background is required on each subject. In this section, we offer a brief summary of distributed spacecraft mission terminology, common parametric cost estimating techniques for Earth orbiting spacecraft, and previous work that has examined the question of costing satellite constellations.

\section{A. Distributed Spacecraft Mission Terminology}

DSM architectures have traditionally been described in terms of four potential classifications [19], which primarily characterize the mission design process and deployment strategy.

1. Constellations: Missions that are designed to utilize multiple spacecraft, placed in specific orbits and in support of a common goal from their inception. Constellation missions can be deployed altogether or in incremental sets. Classic examples of constellation missions include the Global Positioning System (GPS), NASA’s Tracking Data Relay Satellite system (TDRS) [20], MMS, and CYGNSS.

2. Formation Flying Missions: Formation flying missions require multiple spacecraft with specific spatial configuration requirements, such as relative distance or three dimensional spatial relationships, which are controlled through direct sensing capabilities of one spacecraft tracking at least one other spacecraft. Loose formation flying missions impose less stringent relative spatial requirements, while preserving the requirement that the spacecraft orientation be maintained relative to the other spacecraft within the formation. The GRACE mission leveraged this type of DSM architecture through the use of two identical spacecraft placed approximately $220 \mathrm{~km}$ apart [2].

3. Fractionated Spacecraft Missions: Fractionated spacecraft missions distribute the functional capabilities of a traditional, monolithic spacecraft across multiple spacecraft, which in turn can share their resources through wireless networking. The US Defense Advanced Research Projects Agency (DARPA) pursued this mission concept in its Future, Fast, Flexible, Fractionated Free-flying Spacecraft United by Information Exchange (System F6) program, but the project was cancelled in 2013 [21].

4. Ad-Hoc Missions: Ad-hoc missions have so far been defined as those DSMs which are "generated as launch opportunities arise" [22] or become "a DSM after the fact" [19], and therefore cubesatellite DSMs constructed through a series of secondary launch opportunities or individual missions that are combined to support common goals fall within this category. One such joint mission, the Ocean Topography Experiment (TOPEX/Poseidon) and subsequently Jason-1, not only illustrates the concept of an ad-hoc constellation, but also highlights the need for an additional, more nuanced sub-classification for ad-hoc DSM architectures, including the notion of purely ad hoc and temporally distributed spacecraft missions that we propose within this paper.

TOPEX was originally a NASA and JPL based experiment, while Poseidon was being developed by the French space agency, CNES, and both missions were focused on measuring ocean topography. The combined mission, TOPEX/Poseidon, was created by combining these two separate projects and launching a single, jointly developed spacecraft in 1992 [23]. The two agencies then shared the development and operation of a follow on mission known as Jason-1, which launched in 2001. Once Jason-1 was successfully inserted into its orbit, TOPEX/Poseidon and Jason-1 formed what we refer to within this paper as a purely ad-hoc DSM. The two spacecraft were designed separately (not developed concurrently), but the first mission, TOPEX/Poseidon, exerted design influence on Jason-1. Collectively, the two spacecraft supported a common mission objective.

The TOPEX/Poseidon mission officially ended in 2006, but additional follow on missions, the Ocean Surface Topography Mission (OSTM/Jason-2) and Jason-3, were launched in 2008 and 2016 respectively [23]. These follow on missions are not only complete missions in and of themselves, but also contribute to a long-term, common mission objective, to study ocean surface topography. There is clearly significant value added to the science community by the creation of a multi-decadal record. The Landsat Missions have further demonstrated this fact through the generation of the longest duration, Earth imaging effort ever produced [24]. Instances of exented duration missions that consist of many generations of spacecraft are common in both the science and 
commercial communications realms. We therefore propose the term temporally distributed spacecraft mission to address a series of missions that may or may not have overlapping operational lifetimes, and are designed over the course of many years to support a common, long duration mission objective or objectives. We believe these temporally distributed spacecraft missions should be of interest to the cost estimating community because there are likely to be design heritage and learning curve cost savings associated with follow on missions that may not be captured if the missions are considered fully separate entities and because of the distinct type of science added by long-term observations offered by type of architecture. Even if the type of data changes from mission to mission, the extended record and common mission objective, support the notion of follow-on missions as temporally distributed spacecraft missions.

The Afternoon Train (A-Train) represents both a purely ad-hoc and temporally distributed spacecraft mission architecture. In the early 2000 s, four spacecraft were launched into highly similar orbits, somewhat by accident [25]. Similar Earth science missions had requested nearly identical orbits behind Aqua, which launched in 2002. Aura and PARASOL followed in 2004, and CloudSat and CALIPSO were placed in the train in 2006 [26]. Aqua, Aura, CloudSat and CALIPSO created a purely ad hoc constellation; the satellites were leveraged by the Earth science community as a system supporting shared mission goals, and the data gathered from each spacecraft helped to shed light on the data gathered by the others. Follow on missions, PARASOL, GCOM-W1, and OCO2, contributed to the formation of a temporally distributed spacecraft mission. (The Glory satellite mission was also designed to supplement the A-Train as part of a temporally distributed spacecraft mission, but failed to reach its intended orbit.) The additional missions were added to the A-Train to enhance the data being recorded by the original satellites, and to continue the data gathering effort as the original missions approach their conclusion. The common objective has been furthered despite the decommissioning of PARASOL, which was lowered out of configuration in 2013. The early success of the original purely ad-hoc A-Train DSM was likely a contributing factor to the increased interest and acceptance of DSM architectures for Earth observation, as it highlighted the value of varied science instruments taking near-simultaneous measurements to scientists examining global climate change. Then, through the use of a temporally distributed spacecraft mission architecture, scientists have been able to continue to offer scientific insights that would not have been possible with individual missions.

Within these categories, DSMs can be thought of as homogenous, if all of the member satellites are identical, or heterogeneous, if the member satellites are different from one another. We refer the reader to the 2016 (anticipated) paper by Le Moigne et al. for a more detailed discussion of additional terminology and particular DSM orbital configurations [19].

\section{B. Cost Estimation}

\section{Parametric Cost Estimating}

Cost estimating and cost analyses are essential elements of space mission project management. The cost estimating process enables project managers to assess project feasibility, cost risk, and possible alternative designs, as necessary, and allows stakeholders (e.g. Congress, payload/instrument owners) to better understand mission requirements and project development. The NASA Cost Estimating Handbook outlines three cost estimation methodologies: analogy cost estimating, parametric cost estimating, and engineering build-up methodology (also known as "bottom-up" estimating) [27]. In this paper, we have focused exclusively on parametric cost estimating practices, and refer the reader to the NASA Cost Estimating Handbook for additional reading regarding the other methodologies.

Parametric cost estimating relies on the use of historical data and regression analysis to create Cost Estimating Relationships (CERs) that are then used to develop cost estimates based on only key mission cost drivers, which can include diverse mission characteristics such as system mass, number of instruments, or management type (e.g. commercial, government, or military). The advantages of parametric costing practices, in comparison to other methodologies, include statistical validity, objectivity, consistency, and speed. The disadvantages of the parametric method include the time-intensive process of developing CERs and a 'black-box' tendency for inexperienced cost estimators to blindly input and output values without sufficient mission context, which can threaten the transparency and usefulness of the estimate. Furthermore, once a CER has been defined for a particular dataset, it reflects the nature of that set, and it must be assumed that historical trends will hold into the foreseeable future. Therefore, the CER cannot be reliably extended beyond the original parameters and application of a given CER to components of an innovative or paradigm-shifting mission may be inappropriate. Parametric cost estimating is the most appropriate method for early phase design estimates as it requires few detailed design decisions and allows for probabilistic estimating, which can be helpful in design tradeoff analyses and project planning. 
Existing parametric models for space mission cost estimation include a wide range of applications, systems, and objectives. Table 1 presents some widely accepted parametric cost estimating tools that have largely influenced space mission cost estimating in recent decades; we present these models to provide context for this paper, but make no claim to exhaustiveness in this list. Generally, cost estimating methodologies emerge in response to technological trends. The advent of small satellites in the mid 1980's contributed to the development of the Small Satellite Cost Model, and as project intricacy has increased with greater technological capability in recent decades, efforts have been made to develop complexity based cost estimating relationships (CCERs), which enable mission stakeholders to consider schedule and cost as part of the design process, rather than designing a mission first, and assessing cost and schedule demands second [28]. Despite the recent trend toward DSM architectures, a high fidelity DSM cost estimating tool does not yet exist.

Table 1. Common parametric cost estimating models for spacecraft and space missions

\begin{tabular}{|c|c|c|c|c|c|}
\hline Name & Developer & $\begin{array}{c}\text { Original } \\
\text { Release Date }\end{array}$ & $\begin{array}{l}\text { Most Recent } \\
\text { Release Date }\end{array}$ & Scope & Availability \\
\hline $\begin{array}{l}\text { Unmanned } \\
\text { Space Vehicle } \\
\text { Cost Model } \\
(\text { USCM })^{29}\end{array}$ & $\begin{array}{l}\text { Space and Missile } \\
\text { Systems Organization } \\
\text { (SAMSO), Cost } \\
\text { Analysis Division }\end{array}$ & 1969 & June 2015 & $\begin{array}{l}\text { Unmanned, earth orbiting spacecraft; } \\
\text { does not include launch vehicles }\end{array}$ & Public \\
\hline $\begin{array}{l}\text { Small Satellite } \\
\text { Cost Model } \\
(\text { SSCM })^{30}\end{array}$ & Aerospace Corporation & 1995 & January 2015 & $\begin{array}{l}\text { Earth orbiting or near planetary } \\
\text { spacecraft with mass }<1000 \mathrm{~kg} \text {; dataset } \\
\text { is restricted to post }-1990 \text { missions }\end{array}$ & Public \\
\hline $\begin{array}{l}\text { NASA } \\
\text { Instrument } \\
\text { Cost Model } \\
\text { (NICM) }^{31}\end{array}$ & $\begin{array}{l}\text { NASA Cost Analysis } \\
\text { Division and Jet } \\
\text { Propulsion Laboratory }\end{array}$ & 2007 & Spring 2014 & $\begin{array}{l}\text { CERs for specific types of instruments; } \\
\text { found to be low fidelity for Explorer- } \\
\text { class missions } \$\end{array}$ & $\begin{array}{l}\text { Access through } \\
\text { NASA ONCE } \\
\text { Portal }\end{array}$ \\
\hline $\begin{array}{l}\text { NASA } \\
\text { Instrument } \\
\text { Cost Model for } \\
\text { Explorer Class } \\
\text { Missions } \\
(\text { NICM-E) }\end{array}$ & $\begin{array}{l}\text { NASA Cost Analysis } \\
\text { Division and Jet } \\
\text { Propulsion Laboratory }\end{array}$ & Spring 2014 & Spring 2014 & $\begin{array}{l}\text { Instruments intended for flight on } \\
\text { Class } C \text { missions, with substantial } \\
\text { university or research foundation } \\
\text { involvement, and significant design } \\
\text { heritage }\end{array}$ & $\begin{array}{l}\text { Access through } \\
\text { NASA ONCE } \\
\text { Portal }\end{array}$ \\
\hline $\begin{array}{l}\text { Mission } \\
\text { Operations } \\
\text { Cost } \\
\text { Estimating } \\
\text { Tool } \\
(\text { MOCET) })^{32} \\
\end{array}$ & $\begin{array}{l}\text { Aerospace Corporation } \\
\text { and NASA Science } \\
\text { Office For Mission } \\
\text { Assessments }\end{array}$ & $\begin{array}{l}\text { Released } \\
\text { within ONCE } \\
\text { Portal }\end{array}$ & $\begin{array}{l}\text { Released } \\
\text { within ONCE } \\
\text { Portal }\end{array}$ & $\begin{array}{l}\text { Phase E mission costs; planetary, Earth } \\
\text { science, near Earth orbiting missions }\end{array}$ & $\begin{array}{l}\text { Access through } \\
\text { NASA ONCE } \\
\text { Portal }\end{array}$ \\
\hline $\begin{array}{l}\text { NASA Air } \\
\text { Force Cost } \\
\text { Model } \\
\text { (NAFCOM) }^{33}\end{array}$ & $\begin{array}{l}\text { NASA Cost Analysis } \\
\text { Division and Marshall } \\
\text { Space Flight Center }\end{array}$ & $\begin{array}{l}1990 \\
\text { (Released as } \\
\text { NASCOM } \\
\text { hardcopy } \\
\text { database) } \\
\end{array}$ & $\begin{array}{l}2012 \text { (Final } \\
\text { release; } \\
\text { replaced by } \\
\text { PCEC) }\end{array}$ & $\begin{array}{l}\text { Launch vehicles, Crew Exploration } \\
\text { Vehicles, Landers, Rovers, other flight } \\
\text { hardware elements }\end{array}$ & $\begin{array}{l}\text { No longer } \\
\text { available; } \\
\text { retired in } 2012\end{array}$ \\
\hline $\begin{array}{l}\text { Project Cost } \\
\text { Estimating } \\
\text { Capability } \\
\text { (PCEC) }^{33}\end{array}$ & $\begin{array}{l}\text { NASA Headquarters } \\
\text { and Marshall Space } \\
\text { Flight Center }\end{array}$ & May 2014 & August 2016 & $\begin{array}{l}\text { All elements of the NASA Work } \\
\text { Breakdown Structure as defined in } \\
\text { NPD } 7120.5 \mathrm{E} \text {; carries forward select } \\
\text { elements of NAFCOM }\end{array}$ & Yes \\
\hline $\begin{array}{l}\text { Aerospace } \\
\text { Picosatellite } \\
\text { Cost Model } \\
(\text { A-PICOMO) })^{34}\end{array}$ & Aerospace Corporation & $\begin{array}{l}\text { Model was } \\
\text { never publicly } \\
\text { released }\end{array}$ & $\begin{array}{l}\text { Model was } \\
\text { never publicly } \\
\text { released }\end{array}$ & $\begin{array}{l}\text { Satellites with mass much less than } 50 \\
\mathrm{~kg} \text {, with an emphasis on mass less than } \\
10 \mathrm{~kg} \text {; directly motivated by a lack of } \\
\text { applicability of SSCM to cubesatellites }\end{array}$ & $\begin{array}{l}\text { Aerospace } \\
\text { Corporation } \\
\text { internal effort }\end{array}$ \\
\hline
\end{tabular}

$\S$ The NICM-E CER (subsequent row) was released as an addition to NICM VI to address the need for higher fidelity Explorer-class mission instrumentation 


\begin{tabular}{|c|c|c|c|c|c|}
\hline $\begin{array}{l}\text { Constructive } \\
\text { Systems } \\
\text { Engineering } \\
\text { Cost Model } \\
\text { (COSYSMO) }\end{array}$ & $\begin{array}{l}\text { Massachusetts Institute } \\
\text { of Technology and } \\
\text { University of Southern } \\
\text { California }\end{array}$ & 2005 & 2009 & $\begin{array}{l}\text { Systems engineering efforts for large } \\
\text { scale systems (hardware and software) }\end{array}$ & Yes \\
\hline $\begin{array}{l}\text { Technology } \\
\text { Cost and } \\
\text { Schedule } \\
\text { Estimating } \\
(\text { TCASE) })^{2 * *}\end{array}$ & $\begin{array}{l}\text { NASA Headquarters } \\
\text { and SpaceWorks } \\
\text { Enterprises, Inc. }\end{array}$ & $\begin{array}{l}\text { Released } \\
\text { within ONCE } \\
\text { Portal }\end{array}$ & $\begin{array}{l}\text { Released } \\
\text { within ONCE } \\
\text { Portal }\end{array}$ & $\begin{array}{l}\text { Schedule duration and cost ranges for a } \\
\text { new technology development project } \\
\text { (TRL1 - TRL6) }\end{array}$ & $\begin{array}{l}\text { Access through } \\
\text { NASA ONCE } \\
\text { Portal }\end{array}$ \\
\hline
\end{tabular}

\section{Work Breakdown Structure}

The Work Breakdown Structure (WBS) is used to provide a hierarchical representation of all deliverables required to meet the project objectives and is an integral part of the project cost management process [37]. System requirements are used to develop a WBS that accounts for all of the work content to be contributed by all performing project stakeholders, and therefore work not accounted for within the WBS is not considered to be part of the project and is not accounted for in cost estimates [38]. While greater levels of project detail are provided at deeper levels of the WBS, a standard template exists for Levels 1 and 2 of all NASA space flight and technology projects. The space flight project template, as presented in the NASA Work Breakdown Structure Handbook, is provided for reference in Figure 1, and descriptions of each of the Level 2 elements are available within the NASA Work Breakdown Structure Handbook, Appendix C.

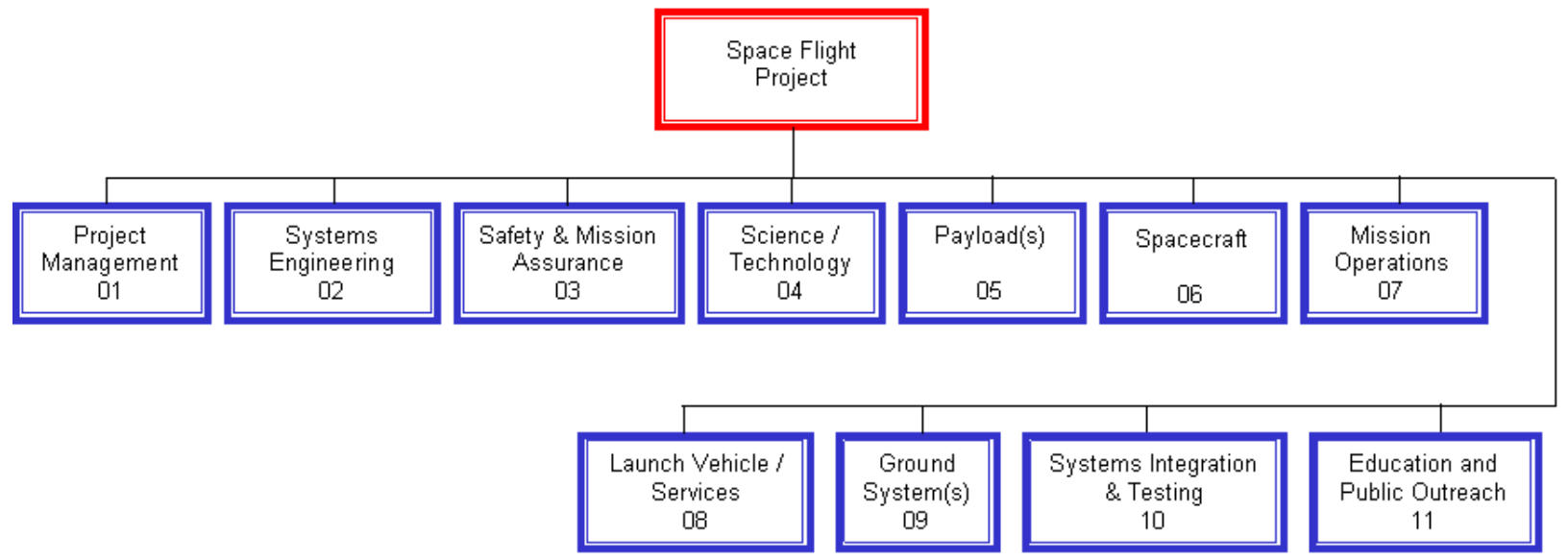

Figure 1. Space Flight Project Standard Level 2 Elements (NASA Work Breakdown Structure Handbook [38])

\section{Previous Work}

Satellite constellation optimization, often subject to a cost objective or constraint, has been explored in previous work. Such optimization problems have been of particular interest, as design-to-cost mission development has become a standard method of managing tight program budgets, while seeking to minimize cost and maximize scientific return. Some previous optimization efforts have implemented cost modules as part of their system model, but these cost modules have been rooted in traditional CERs and costing best practices as presented by Wertz and Larson in their book on Space Mission Analysis and Design, rather than based in costing strategies that have been tailored for DSMs $[15,16,17]$. In the most simplistic cases, the cost estimate is produced costing a single satellite and multiplying it $n$ times to achieve the cost of the entire DSM, resulting in an estimate that fails to account for the nuances of DSM development and the cost savings that can be achieved by developing multiple spacecraft in parallel [19]. Therefore, the use of traditional costing practices may threaten the validity of the optimization results.

\footnotetext{
** TCASE is an analogy and decision tree based model and was the second most downloaded model on the ONCE portal in 2014 and 2015 [36]. Despite the fact that this is not a parametric approach, it is being included here for reference given its widespread use.
} 
Nag et. al addressed the challenges of using traditional cost estimating processes for DSM architectures in their 2014 work, specifically citing the low reliability of existing learning curve factors when applied to DSM member satellites, the lack of parametric cost tools intended for satellites with mass less than $20 \mathrm{~kg}$, and insufficient understanding of small satellite DSM operations practices as a barrier to accurate costing [7].

The need for reliable cost estimating processes for DSM architectures, as highlighted by these previous efforts, is the motivation for this survey. In the following sections, we build upon the work presented by Nag et. al [7] by identifying additional challenges to DSM cost estimating. We recognize that DSM architectures will inherently challenge traditional cost estimating assumptions and therefore make preliminary recommendations for improving future DSM cost estimation.

\section{Methodology}

To enable our investigation, we have developed a cost estimating tool for constellation missions. Our aggregate cost model combines widely accepted CERs from a variety of existing cost estimating tools into an automated costing tool capable of enabling relative cost trades for candidate architectures [39]. The development of this aggregate model has allowed us to investigate the current state of the art in cost estimating technology and how those tools can be applied to DSM architectures. Ultimately, our aggregate cost estimating tool will be incorporated within the NASA GSFC Tradespace Analysis Tool for Constellations (TAT-C), which is currently undergoing development [40]. TAT-C will enable pre-Phase A DSM mission analysis with respect to user defined performance and cost requirements. Given the pre-Phase A nature of TAT-C, a high fidelity, exact-value cost estimate is not possible, as project scope creep, schedule delays, and other system level considerations cannot be sufficiently forecast or addressed. We have chosen not to address scheduling within our model and instead assume that the project is executed at the optimal pace, therefore incurring neither standing army nor rush development costs. Shao et al. took a similar approach in their 2014 work on performance based cost modeling for small satellites, but leveraged only a subset of the existing models we have incorporated into our tool [41]. As stated previously, while we present a high level discussion of the cost model we have developed within this paper, we reserve a more thorough discussion of the tool and associated results for a later paper, once TAT-C has been released.

A preliminary, high-level representation of our aggregate cost model is presented in Figure 2. We have chosen to leverage existing models rather than developing CERs specifically for DSM or constellation architectures in part because the use of DSM architectures for Earth science missions is still relatively new, and as such the data set would be skewed significantly toward programs with low levels of experience and high implementation costs (e.g. new facilities, specific personnel needs, additional research and development efforts), and because cost data is often competition sensitive and therefore not publicly available at the level of detail that would be required to establish high fidelity CERs. Additionally, the existing toolset has the benefit of decades of use by the costing community. By leveraging this collective experience, we have attempted to identify and address existing gaps, rather than creating a new tool with a new set of limitations. We have limited ourselves to the use of publicly available CERs and cost estimating tools.

The model accepts an input file of DSM characteristics, including a list of observatories ${ }^{\dagger \dagger}$, mission owner specifications, and ground stations. A contextual assessment of the DSM architecture is formulated according to the number and distribution of satellites within the architecture, as well as assessing the number of unique spacecraft within the architecture (and by extension the number of copies of a given satellite). This information, in conjunction with satellite mass, is used to select appropriate learning curve factors [7, 17] and spacecraft bus cost reliability factors [14]. The mission owner and satellite technology readiness level (TRL) are collectively used to select an appropriate scaling factor for research and development costs, as discussed by Wertz and Larson [17].

The spacecraft parameters, including system wet and dry mass, TRL, and payload type, among others, and then assesses the spacecraft bus cost using CERs from either the Unmanned Space Vehicle Cost Model (USCM) [29] or the Small Satellite Cost Model (SSCM) [30] depending on the appropriate mass classification. While not currently implemented, we are developing a method of addressing satellites at the lowest end of the mass spectrum (those less than $50 \mathrm{~kg}$ ). Previous research has noted the inappropriateness of the SSCM for microsatellites and cubesatellites [7, 42], and we plan to address this need within our model and in future work. The payload is then costed using the NASA Instrument Cost Model (NICM) [31].

Mission operations are calculated using a combination of the CERs for Earth science missions found within the Mission Operations Cost Estimation Tool (MOCET) [32], USCM, and established best practices [17]. Wraps costs,

\footnotetext{
$\Uparrow$ We use the term observatory here to refer to a complete satellite, including the instrument (payload) and supporting subsystems (spacecraft or spacecraft bus).
} 
including program management, systems engineering, integration and test, and satellite-side launch operations costs are calculated using CERs from USCM, SSCM and Larson and Wertz. Launch vehicle costs are calculated according to available pricing information from a range of commercial and government launch services providers.

The final step of the cost estimating process accounts for cost risk and records relevant assumptions. A common threat to the usefulness of automated cost estimating tools is their 'black box' nature, which can obscure important caveats to the estimation. At all decision points within our tool, relevant information regarding the nature of the decision is recorded and output as part of the final cost documentation. The output includes these caveats and a probabilistic distribution of the cost estimate for the mission lifecycle, as well as recurring and nonrecurring cost for each of the space flight project standard WBS Level 2 elements.

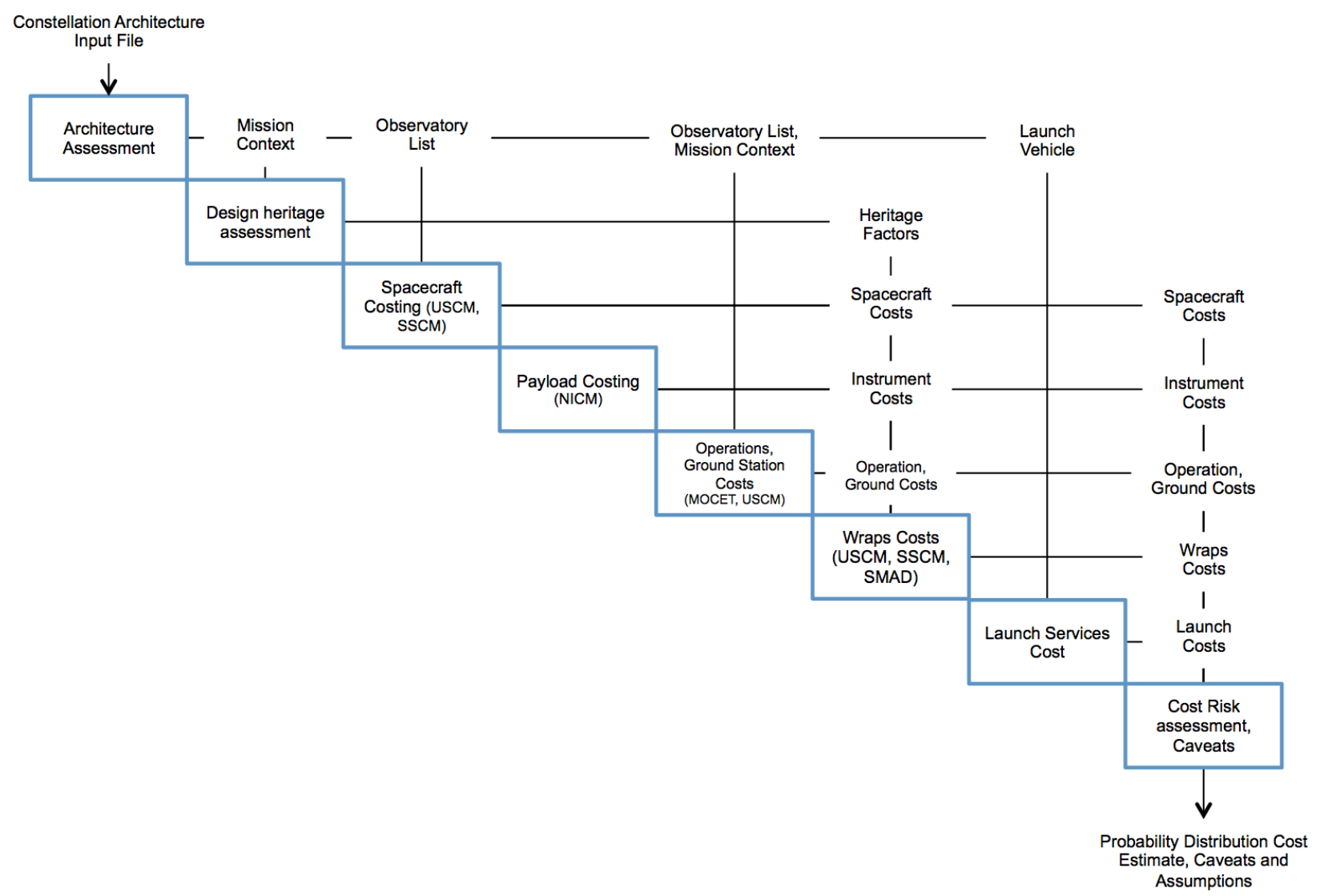

Figure 2. High-level representation of aggregate cost model

\section{Results and Recommendations}

Building the aggregate cost model required us to examine each step of the DSM development process and compare the available cost assessment tools to current trends in DSM development. Below, we present a summary of our observations and ways in which the existing parametric cost estimating toolkit may not reflect the emerging DSM paradigm, and therefore may not be reliable for DSM cost estimation. Given that cost is often incurred in an attempt to mitigate risk, we found that many of the areas in which DSM architectures are presenting new risks, or mitigating risks in new ways, are the same areas in which DSM costs most notably deviate from previous cost estimating capabilities: design iteration, systems integration and testing, and mission operations. Technology development during mission development presents additional challenges for small satellite DSMs.

\section{Design Iteration}

Iteration is a common process within systems engineering, and many iterations of a single design may be required before multidisciplinary, and often competing, objectives can be satisfied. Given that the optimization process for DSM architectures is subject to additional requirements (as compared to a single observatory) and is likely to result in a set of optimal solutions rather than a single optimum [16], architecture trade studies can help to avoid costly rework after the design has been finalized and the manufacturing process has begun. Design iteration 
should therefore be considered an essential deliverable within the development process and accounted for as a systems engineering cost.

However, the WBS Handbook does not address the need for system rework (which includes design iteration), but instead states that "Rework, Retesting and Refurbishing are additional non-product oriented terms and are not usually recommended as appropriate" for inclusion within the WBS [38]. We argue that because DSM architectures are not the 'usual' case, design iteration would be an appropriate element of the Element 6 Spacecraft WBS hierarchy. We further extend this argument to rework, retesting, and refurbishment. While rework for a single satellite is limited to a single flight system, constellation mission rework can involve changes to a greater number of instruments and the costs of rework scale accordingly. This cost escalates as the satellite moves through the design process; the cost of correcting a design flaw or implementation error increases by approximately an order of magnitude for each phase of the development cycle [17]. Therefore, available cost margins may not fully allow for the possibility of significant design changes to multiple spacecraft and provide insufficient protection from cost overruns. Given that cost overruns are of particular concern for Earth science missions [8], this could be especially beneficial to Earth science project managers.

The MMS mission encountered problems with the Fast Plasma Instrument (FPI) that underscore the need for specific rework allowances. During the integration phase, optocouplers within FPI were found to be unsuitable for the original mission requirements. Because each of the four spacecraft included the FPI instrument suite, a total of 288 optocouplers were required, and their failure to meet mission requirements presented a serious threat to the mission's science return. The resulting rework caused significant cost overruns, and before the completion of the integration and test phase, MMS had used almost all of its available budget [43]. As of the 2014 GAO project update on MMS, NASA GSFC (the MMS project office) had committed \$2.15 million to correct problems associated with the optocouplers. The resulting schedule delays also contributed to significant cost growth. Once the MMS octocoupler rework was complete, the NASA GSFC thermal vacuum chamber was needed for testing of the James Webb Space Telescope (JWST), which was given testing priority. The testing delay, and other delays associated with the 2013 government shutdown, resulted in a launch delay from October 2014 to March 2015 and additional cost growth. Ultimately, MMS experienced approximately 3\% lifecycle cost growth ${ }^{\$+}$, resulting in a final lifecycle cost of $\$ 1.083$ billion $[45,46]$.

We recommend that design iteration, which has the potential to result in design rework, retesting, and refurbishment, be specifically included within WBS Element 6 for constellation missions as an essential spacecraft deliverable required to achieve project objectives. While this recommendation does not pertain specifically to parametric cost estimating methodologies, it addresses an opportunity for program managers and cost estimators to develop cost management practices that more completely reflect the current state of DSM development practices.

Multiplicative factors are often applied to scale research, development, test and evaluation (RDTE) costs up or down depending on the extent of development heritage associated with a satellite design and the amount of design iteration that may be necessary to leverage prior work. Within the our aggregate cost model, we have applied these factors to scale back RDTE costs for copies of a satellite within a constellation architecture. Satellites with a higher payload TRL level but common bus design can similarly be scaled up. Satellites within purely ad-hoc and temporally distributed space missions present an opportunity for developers to leverage prior knowledge and existing on-orbit assets to inform the nature of their design, which will result in specific design requirements that warrant consideration as iterations on a previous effort. For temporally distributed spacecraft missions, the ability to update system functionality by adding technologies intended to target system weaknesses may offer science benefits but require highly specialized design, and therefore traditional heritage factors may not remain relevant.

We intend to examine the applicability of existing design heritage factors to Earth science constellations and ad-hoc DSMs in a future work.

\section{Systems Integration and Testing}

Satellite integration typically consists of mating the spacecraft bus and payload and then testing the system as a complete unit, but unique constellation technologies are changing the procedures required to ensure functionality on orbit and presenting opportunities to reduce costs. For example, each member of a Class D small satellite constellation may undergo less extensive testing than a similar individual spacecraft might, in order to reserve test funding for constellation-level test efforts. In short, system integration accounts for the integration of each individual observatory and the constellation fleet as a whole and funding must be carefully split among these efforts.

\footnotetext{
${ }^{*}$ For additional information pertaining to MMS cost and schedule overruns, we refer the reader to 2009 National Academies publication, "A Performance Assessment of NASA's Heliophysics Program" Chapter 2, Section 2.2. [44]
} 
Furthermore, many constellation integration and test practices have been developed specifically for DSMs, and the data sets behind existing parametric tools are primarily comprised of monolithic spacecraft. Previously existing CERs may not accurately capture the integration and tests costs of DSM architectures, exemplifying the concern presented previously regarding the applicability of parametric cost estimating methodologies to innovative technologies.

Satellite manufacturing is a precise, highly specialized procedure. To reduce manufacturing costs, experts have recommended that program managers incorporate manufacturing feasibility as a system design requirement and rely more heavily on concurrent engineering practices [17]. This could increase spacecraft design costs, in terms of schedule and personnel requirements, but reduce manufacturing costs. Careful procedure planning and maintenance could further streamline the manufacturing process and eliminate excessive overhead. However, investments in manufacturing must account for the number of copy satellites to be produced and/or the amount of design heritage from one DSM project to the next. A commercial company constructing hundreds of satellites has much more to gain from low manufacturing costs than experimental science mission developers, such as NASA GSFC or the Jet Propulsion Laboratory (JPL). Developers of scientific constellation programs may benefit less from developing an assembly line in the traditional sense, in which the product moves down the line of processes, and more from developing an assembly line in which the process and manufacturing personnel move from product to product. This moveable-process assembly line approach requires highly specialized teams with interdisciplinary skills, which may incur atypical costs. For small satellites in particular, this may enable the detailed manufacturing processes that accompany miniaturized technologies to be performed with greater reliability than in a traditional manufacturing environment. The cost management result of this manufacturing process is that spacecraft manufacturing is a project deliverable more appropriately categorized under WBS Element 10, Systems Integration and Testing, than it is as an element unique to the individual spacecraft, as it is under WBS Element 6 . We recommend manufacturing be considered as an element of systems integration and testing (WBS10) for constellation missions and encourage cost estimating model developers to develop CERs that address the unique nature of satellite constellation manufacturing and integration.

Wertz and Larson have argued that the constellation testing phase has the greatest cost and schedule saving improvements, not only because testing multiple copies of identical systems can be seen as redundant, but also because early design flaw detection prevents the need for extensive rework [17]. They have encouraged constellation mission developers to design for accessibility at later stages to enable lower cost defect correction without compromising mission objectives. MMS is again a suitable example of how these practices might have been implemented to save costs. Substantial changes to the mission, including the management of the satellites' power budgets, were made to accommodate the optocouplers, even after the failed components had been replaced with new ones [45]. Early testing and design accessibility could have allowed for alternate repair or design rework that may have limited the mission profile changes or cost overruns. Earth science program managers are increasingly considering accessibility as a method for mitigating the possibility of late changes in both large and small spacecraft. For larger satellites, integration and test may also include the verification of intersatellite link technologies and require the testing of spatial orientation sensors. These new procedures may also require additional testing equipment or facilities, which could significantly raise the cost of testing.

Constellations offer a unique opportunity for program managers to distiguish between reliable and redundant satellites. A satellite that can tolerate a subsystem failure is reliable, while a satellite that is a non-esssential, exact replica of another member satellite within the constellation is redundant. If a constellation is capable of meeting mission objectives after the loss of a member satellite, the constellation itself is fault tolerant even if the member satellites are not. Designers can therefore accept greater risk at the subsystem and satellite level, as long as the constellation architecture can tolerate the decreased functionality or loss of a member satellite. Designing this fault tolerance requires consideration of constellation performance plateaus, which are commonly considered when designing deployment or degradation plans. The ability to reconfigure constellations on-orbit can also increase the system robustness [17]. This system-level fault tolerance may result in less stringent testing requirements for individual member satellites and significant cost savings. We recommend that program managers and cost estimators consider the nuances of constellation fault tolerance and system testing when allocating project funding and considering the tradeoffs between individual satellite and DSM risk. The cost implications of constellation performance plateaus warrant further research and should be examined carefully by cost estimators working on projects that are tolerant to the loss of one or more observatories.

\section{Mission Operations}

Satellite constellations and DSMs operations can be simplified by operating a fleet of observatories as a single unit or through the increased use of automated operations practices. The ability to manage an entire fleet of satellites 
simultaneously offers significant cost and risk savings with respect to orbit maintenance and communications [47]. Autonomous system operation reduces the need for some ground station equipment, facilities, and personnel, but also results in increased software development and testing costs and software specific risks, which have been shown to contribute to accidents in unique ways within autonomous aerospace systems [48]. DSM operations therefore present new tradeoffs between cost and risk.

The cost savings associated with treating a DSM as a single entity include the decreased demand for personnel under nominal operating conditions, but an increased need for off-nominal operations resources, as demonstrated by NASA's Space Technology 5 mission, which consisted of three 25 kilogram satellites [49]. The mission encountered a series of anomalies when it was first deployed on orbit, including false signals from the sun sensors and inappropriate constellation configuration. In response to these challenges, the "ST5 Anomaly Team" was activated in an attempt to preserve mission performance [50]. Despite the initial challenges and largely due to the efforts of the anomaly team, ST5 was able to achieve its objectives. Toward the end of the 100-day mission, ST5 also completed a weeklong 'lights out' operating period. During this operating phase, the constellation used a set of preprogrammed commands to function without ground station input [50]. Previous work has argued that fully autonomous constellation orbit maintenance could simplify and reduce the cost of constellation operations [47].

The cost considerations for constellation operation are not limited to planned maneuvers or autonomous operating conditions. Extended constellation operating lifetimes will likely represent an additional program cost for future missions. Many recent Earth science missions have surpassed their planned mission durations, and NASA currently spends approximately $10 \%$ of its Earth science budget maintaining and processing data from spacecraft that have exceeded their operational lifetimes [51]. Decommissioning multiple spacecraft simultaneously may also result in additional costs to mitigate risk and achieve NASA orbital degree requirements.

In light of these trends in DSM operations, we recommend that the current approach to DSM operations cost estimating be reconsidered, including the development of a new CER that addresses the degree of autonomy built into a given constellation operation plan. Many sources currently use software development costs as a driver for operating costs [17], and others base their estimates on mission class or number of instruments [32]. These cost drivers may not fully capture the operating considerations presented above.

\section{Technology Development Costs}

Launched in 2006, ST5 was intended to introduce several new technologies and achieve an extensive set of technological objectives, including the deployment of three satellites working as a single system, miniaturized components, and an autonomous operating period [52]. The mission met its intended objectives, but also experienced $62.5 \%$ cost growth [53]. A detailed explanation of the reasons behind this cost growth is not available, but subject matter experts have expressed concerns over the ability of programs to raise TRL on small satellite missions and simultaneously achieve aggressive science goals. This impact may be felt to a lesser extent by temporally distributed spacecraft missions, which can leverage the experience gained by prior missions to inform decisions about incorporating low-TRL technologies. We plan to address the cost growth associated with technology development missions in future work.

\section{Conclusion}

This paper constitutes an assessment of weaknesses within the existing parametric cost estimating toolkit, as it pertains to distributed spacecraft mission architectures, and builds upon the work presented by Nag et al. in their 2014 work. By developing an aggregate approach to constellation cost estimating, we were able to compare existing perspectives and models for satellite cost estimation to the current trends in experimental DSM development. We identified three areas in particular where existing methodologies are ill suited to address the innovations of the emerging DSM paradigm and made the following recommendations for further development in this realm.

The existing ad-hoc constellation term should be supplemented by two subclassifications: purely ad hoc DSMs and temporally distributed spacecraft missions. This subclassification better captures the unique nature of follow on missions and programs designed to continuously contribute to a data record over the course of many decades. Design iteration, and by extension product rework, retesting, and refurbishment, should be specifically included within DSM and constellation work breakdown structures, and should be considered essential project deliverables by project management. These elements should be incorporated as part of Work Breakdown Structure Element 6 . The manufacturing of DSM member satellites is increasingly being addressed as a parallel process, and current practices are challenging traditional assumptions regarding system integration and testing procedures. We have argued that spacecraft manufacturing be incorporated into Work Breakdown Structure Element 10. Existing parametric cost estimating relationships likely do not fully capture the extent of the changes to DSM satellite 
manufacturing and testing, and we believe that cost estimating models should be updated to reflect these integration and test practices. The possibility of building redundant architectures that allow for the loss of member satellites should be considered when costs are allocated to mitigate mission risk during both the design and test phases. In light of the unique cost and risk tradeoffs presented by DSM operating practices, we recommend that cost estimating relationships for DSM operations be re-evaluated for accuracy and that new cost estimating relationships and/or multiplicative factors be developed, as necessary. In future work, we will present the details and results of the aggregate cost model and its incorporation within TAT-C. We also plan to examine the appropriateness of existing design heritage factors for Earth science constellation and ad-hoc DSM architectures, and the cost of raising the technological readiness level of spacecraft component technologies as part of small satellite DSMs.

Distributed spacecraft missions have the potential to offer new benefits to Earth scientists, but fully capturing those benefits will hinge on accurate cost estimating to support the mission proposal, development, and management processes. This survey constitutes an initial attempt at identifying and addressing the shortcomings of the existing cost estimating framework as it can be applied to DSMs. We have offered preliminary recommendations for improvements to these efforts and identified fruitful venues for future research in the realm of DSM cost estimation.

\section{Acknowledgments}

Guidance and support has generously been provided by the Massachusetts Institute of Technology and NASA Goddard Space Flight Center. This research is supported by the National Science Foundation Graduate Research Fellowship under Grant No. 1122374. Any opinion, findings, and conclusions or recommendations expressed in this material are those of the authors and do not necessarily reflect the views of the National Science Foundation.

\section{References}

1. S. Nag, J.J. LeMoigne, D.W. Miller, O.L. de Weck, "A Framework for Orbital Performance Evaluation in Distributed Space Missions for Earth Observation", IEEE Aerospace Xplore 10.1109/AERO.2015.7119227, ISBN: 978-1-47995379-0, March 2015.

2. "GRACE - Gravity Recovery and Climate Experiment." GRACE - Gravity Recovery and Climate Experiment. University of Texas, 20 Aug. 2010. Web. 21 June 2016.

3. United States. Government Accountability Office. Additional Knowledge Would Better Support Decisions about Disaggregating Large Satellites (GAO-15-7). N.p.: Government Accountability Office, 2014. Print.

4. NASAESTO. "NASA Earth Science at 2030: A Vision of the Future." YouTube. NASA Earth Science Technology Office, 01 Aug. 2012. Web. 19 July 2016.

5. National Aeronautics and Space Administration. NASA Newsroom. NASA Selects Low Cost, High Science Earth Venture Space System (12-203). NASA, 18 June 2012. Web. 25 June 2016.

6. Sanchez Net, Marc, Daniel Selva, and Alessandro Golkar. "Exploring classification algorithms for early mission formulation cost estimation." Aerospace Conference, 2014 IEEE. IEEE, 2014.

7. S. Nag, J.J. LeMoigne, O.L. de Weck "Cost and Risk Analysis of Small Satellite Constellations for Earth Observation", IEEE Aerospace Xplore 10.1109/AERO.2014.6836396, ISBN: 978-1-4799-5582-4, March 2014.

8. Sega R., de Weck O.L, et al., "Controlling Cost Growth of NASA Earth and Space Science Missions" By Committee on Cost Growth in NASA Earth and Space Science Missions, National Research Council (NRC) of the National Academy of Sciences, ISBN-13: 978-0-309-15737, Washington. D.C., July 2010.

9. $\quad$ De Selding, Peter B. "First Batch of Iridium Next Satellites Good to Go for July SpaceX Launch - SpaceNews.com." SpaceNews.com. N.p., 29 Apr. 2016. Web. 22 July 2016.

10. De Selding, Peter B. "OneWeb Satellites to Open Factory in Florida with Eyes on Business beyond OneWeb SpaceNews.com." SpaceNews.com. N.p., 18 Apr. 2016. Web. 22 July 2016.

11. "MMS Mission Overview." NASA. Ed. Rob Garner. NASA, 22 Oct. 2015. Web. 30 June 2016.

12. "TROPICS: Mission Overview." Mission Overview. MIT Lincoln Laboratory, 2015. Web. 1 June 2016.

13. Bearden, David A. "Small-satellite costs." Crosslink 2.1 (2001): 32-44.

14. Rasmussen, Amy L. "Cost models for large versus small spacecraft." SPIE's International Symposium on Optical Science, Engineering, and Instrumentation. International Society for Optics and Photonics, 1998.

15. Budianto, Irene A., and John R. Olds. "Design and deployment of a satellite constellation using collaborative optimization." Journal of spacecraft and rockets 41.6 (2004): 956-963.

16. Underwood J., de Weck O.L., Chan S., Samuels A., Shah N. "Optimization of Hybrid Satellite Constellations using Multiple Layers and Mixed Circular-Elliptical Orbits", AIAA-2004-3205, 22nd AIAA International Communications Satellite Systems Conference and Exhibit, Monterey, California, May 9-12, 2004.

17. Wertz, James Richard., and Wiley J. Larson. Space Mission Analysis and Design. 3rd ed. Torrance, CA: Microcosm, 1999. Print.

18. Howard, Joseph, Dipak Oza, and Danford S. Smith. "Best Practices for Operations of Satellite Constellations." (2006). 
19. J. Le Moigne, J.C. Adams, P. Dabney, D. Leisawitz, F. Lemoine, S. Nag, W. Powell, D. Smith, K. Thome, and S. Tompkins, "An Overview of Distributed Spacecraft Missions (DSM)", IEEE Journal of Selected Topics in Applied Earth Observations and Remote Sensing (JSTARS), in preparation.

20. $\quad$ "TDRS Home | Goddard Space Flight Center." TDRS Home | Goddard Space Flight Center. NASA, 2 Oct. 2014. Web. 01 Aug. 2016.

21. Ferster, Warren. "DARPA Cancels Formation-flying Satellite Demo." SpaceNews.com. N.p., 17 May 2013. Web. 01 Aug. 2016.

22. Marinan, Anne, Austin Nicholas, and Kerri Cahoy. "Ad hoc CubeSat constellations: Secondary launch coverage and distribution." Aerospace Conference, 2013 IEEE. IEEE, 2013.

23. "Missions." Ocean Surface Topography From Space. Ed. Margaret Srinivasan. NASA Jet Propulsion Laboratory, n.d. Web. 01 Aug. 2016.

24. "Landsat." Landsat. US Geological Survey, 23 May 2016. Web. 26 July 2016.

25. NASA. N. Introducing the A-Train. NASA News. NASA, 26 Oct. 2010. Web. 26 July 2016.

26. $\quad$ "The Afternoon Constellation." National Aeronautics and Space Administration. Ed. Steven Platnick. NASA, 5 June 2012. Web. 26 July 2016.

27. NASA, NASA. "Cost Estimating Handbook: Version 4.0." Washington, DC (2015).

28. Filippazzo, Giancarlo. "Complexity based cost estimating relationships for space systems." Aerospace Conference, 2004. Proceedings. 2004 IEEE. Vol. 6. IEEE, 2004.

29. $\quad$ Nguyen, Phu, et al. "Unmanned Space Vehicle Cost Model." US Air Force Space and Missile Systems Center (SMC/FMC) 2430 (1994): 90245-4687.

30. Lao, N. Y., T. J. Mosher, and J. M. Neff. "Small Satellite Cost Model, Version 98 InTRO." (1999).

31. Habib-Agahi, Hamid, Joe Mrozinski, and George Fox. "NASA instrument cost/schedule model Hamid Habib-Agahi." Aerospace Conference, 2011 IEEE. IEEE, 2011.

32. Hayhurst, Marc, Shirin Eftekharzadeh, Brian Wood, Vishnu Jyothindran, Robert Kellogg, Cindy Daniels, Lissa Jordin, and Washito Sasamoto. "Mission Operations Cost Estimation Tool (MOCET)." 2015 NASA Cost Symposium. Ames Research Center, Moffett Field, CA. NASA 2015 Cost Symposium Presentations. NASA Cost Analysis Division, 2015. Web. 22 July 2016.

33. $\quad$ "PCEC - Project Cost Estimating Capability." NASA. Ed. Bill Keeter. NASA, 18 Aug. 2014. Web. 02 Aug. 2016.

34. Boghosian, Mary. "Cost Estimating Methodology for Very Small Satellites: A-PICOMO (Aerospace Picosatellite Cost Model)." 1st Interplanetary CubeSat Workshop. Cambridge, MA. ICubeSat, 2012. Web. 27 July 2016.

35. "COSYSMO." COSYSMO. Massachusetts Institute of Technology, 2016. Web. 08 Aug. 2016.

36. John, James K., Eric Plumer, Mike Blandford, and Julie McAfee. "One NASA Cost Engineering Database (ONCE)." NASA 2015 Cost Symposium. Ames Research Center, Moffett Field, CA. 29 Apr. 2016. Lecture.

37. Shishko, Robert, and Robert Aster. "NASA systems engineering handbook." NASA Special Publication 6105 (1995).

38. NASA Headquarters. Earned Value Management Office. NASA Work Breakdown Structure Handbook. NASA, 2010. Web. 25 June 2016.

39. Foreman, Veronica, Jacqueline Le Moigne, and Olivier De Weck. "Satellite Constellation Cost Modeling: An Aggregate Model." ESTF2016. Proc. of Earth Science Technology Forum 2016, Annapolis, MD. NASA Earth Science Technology Office, 13 July 2016. Web. 15 July 2016.

40. Le Moigne, Jacqueline. "A Trade-space Analysis Tool for Constellations." Earth Science Technology Forum 2016. Annapolis, MD. 14 June 2016. Lecture.

41. Shao, Anthony, Elizabeth A. Koltz, and James R. Wertz. "Performance Based Cost Modeling: Quantifying the Cost Reduction Potential of Small Observation Satellites." AIAA Reinventing Space Conference, AIAA-RS-2013-1003, Los Angeles, CA, Oct. 2013.Bearden, David A. "Small Satellite Costs." Crosslink. Aerospace Corporation, 2000. Web. 6 Jun. 2016.

42. Brumbaugh, Katharine Mary. The Metrics of Spacecraft Design Reusability and Cost Analysis as Applied to CubeSats. Thesis. The University of Texas at Austin, 2012. N.p.: n.p., n.d. Print.

43. United States. Government Accountability Office,. NASA Assessments of Selected Large-Scale Projects: Report to Congressional Committees. Washington, D.C.: United States Government Accountability Office, 2014. 12+. Print.

44. United States. National Research Council. Committee on Heliophysics Performance Assessment. A Performance Assessment of NASA's Heliophysics Program. Washington DC: National Academies, 2009. 30-31. Print.

45. Leone, Dan. "After Dodging Bullets in Development, MMS Set for Launch." SpaceNews.com. N.p., 09 Mar. 2015. Web. 03 Aug. 2016.

46. United States. Office of the Inspector General. Office of Audits. AUDIT OF NASA'S JOINT COST AND SCHEDULE CONFIDENCE LEVEL PROCESS (Report No. IG-15-024). Washington DC: n.p., 2015. 2-5. Print.

47. Wertz, James R., et al. "Autonomous constellation maintenance." Mission Design \& Implementation of Satellite Constellations. Springer Netherlands, 1998. 263-273.

48. Foreman, Veronica L., et al. "Software in military aviation and drone mishaps: Analysis and recommendations for the investigation process." Reliability Engineering \& System Safety 137 (2015): 101-111.

49. $\quad$ "Space Technology 5 (ST5)." EoPortal Directory - Satellite Missions. European Space Agency, n.d. Web. 03 Aug. 2016.

50. O'Donnell, James R., et al. "Space Technology 5 launch and operations." (2007). 
51. Freilich, Michael. "Forum Welcome \& Plenary Address." Earth Science Technology Forum 2016. Annapolis, MD. 14 June 2014. Speech.

52. Carlisle, Candace C., and Eric J. Finnegan. "Space Technology 5: pathfinder for future micro-sat constellations." Aerospace Conference, 2004. Proceedings. 2004 IEEE. Vol. 1. IEEE, 2004.

53. Amer, Tahani R. Development of Risk Uncertainty Factors from Historical NASA Projects. Diss. Old Dominion University, 2011. 